\title{
Encapsulation of Antifungals in Micelles Protects Candida albicans during Gall-Bladder Infection
}

\author{
Shih-Hung Hsieh ${ }^{1,2}$, Sascha Brunke ${ }^{3}$ and Matthias Brock ${ }^{1,2 *}$ \\ ${ }^{1}$ Microbial Biochemistry and Physiology, Leibniz Institute for Natural Product Research and Infection Biology, Hans Knoell \\ Institute, Jena, Germany, ${ }^{2}$ Fungal Genetics and Biology Group, School of Life Sciences, University of Nottingham, \\ Nottingham, UK, ${ }^{3}$ Microbial Pathogenicity Mechanisms, Leibniz Institute for Natural Product Research and Infection Biology, \\ Hans Knoell Institute, Jena, Germany
}

\section{OPEN ACCESS}

Edited by:

Dominique Sanglard,

University of Lausanne, Switzerland

Reviewed by:

Rajendra Prasad,

Jawaharlal Nehru University, India

Dimitrios P. Kontoyiannis,

University of Texas MD Anderson

Cancer Center, USA

${ }^{*}$ Correspondence:

Matthias Brock

Matthias.brock@nottingham.ac.uk

Specialty section:

This article was submitted to Fungi and Their Interactions,

a section of the journal

Frontiers in Microbiology

Received: 14 December 2016

Accepted: 17 January 2017

Published: 01 February 2017

Citation:

Hsieh S-H, Brunke S and Brock M (2017) Encapsulation of Antifungals in Micelles Protects Candida albicans during Gall-Bladder Infection.

Front. Microbiol. 8:117.

doi: 10.3389/fmicb.2017.00117
Candida albicans is a dimorphic fungus that colonizes human mucosal surfaces with the potential to cause life-threatening invasive candidiasis. Studies on systemic candidiasis in a murine infection model using in vivo real-time bioluminescence imaging revealed persistence of C. albicans in the gall bladder under antifungal therapy. Preliminary analyses showed that bile conferred resistance against a wide variety of antifungals enabling survival in this cryptic host niche. Here, bile and its components were studied for their ability to reduce antifungal efficacy in order to elucidate the underlying mechanism of protection. While unconjugated bile salts were toxic to C. albicans, taurine, or glycine conjugated bile salts were well tolerated and protective against caspofungin and amphotericin B when exceeding their critical micellar concentration. Microarray experiments indicated that upregulation of genes generally known to mediate antifungal protection is not involved in the protection process. In contrast, rhodamine $6 G$ and crystal violet in- and efflux experiments indicated encapsulation of antifungals in micelles, thereby reducing their bioavailability. Furthermore, farnesol sensing was abolished in the presence of conjugated bile salts trapping C. albicans cells in the hyphal morphology. This suggests that bioavailability of amphiphilic and hydrophobic compounds is reduced in the presence of bile. In contrast, small and hydrophilic molecules, such as cycloheximide, flucytosine, or sodium azide kept their antifungal properties. We therefore conclude that treatment of gall bladder and bile duct infections is hampered by the ability of bile salts to encapsulate antifungals in micelles. As a consequence, treatment of gall bladder or bile duct infections should favor the use of small hydrophilic drugs that are not solubilised in micelles.

Keywords: conjugated bile salts, caspofungin, farnesol, rhodamine 6G, critical micelle concentration

\section{INTRODUCTION}

The dimorphic fungus Candida albicans is frequently found as a commensal on mucosal surfaces. In addition, it causes life-threatening systemic infections in patients with risk factors, such as diabetes, central line catheters, cancer, or organ transplantation (Akpan and Morgan, 2002; Cassone and Cauda, 2012; Gavalda et al., 2014; Teoh and Pavelka, 2016). To control systemic 
candidiasis, the echinocandin caspofungin, the polyene macrolide amphotericin B or azoles are commonly used (Gullo, 2009; Li et al., 2015; Matthaiou et al., 2015). To follow antifungal therapy efficacy in a systemic murine infection model an in vivo bioluminescence imaging system was recently developed that visualizes invasive disease in realtime and in temporal and spatial resolution (Jacobsen et al., 2014). Systemic infection revealed a rapid manifestation of disease in kidneys with bioluminescence signals correlating with fungal burden. A subsequent therapy approach with initial caspofungin treatment and fluconazole de-escalation showed rapid clearance of infection from kidneys, and mice appeared clinically inconspicuous after initiation of treatment. Unexpectedly, some mice from the therapy group developed bioluminescence signals from the gall bladder (Jacobsen et al., 2014) and living C. albicans cells were shed with the release of bile from the gall bladder, potentially leading to a re-colonization of the intestinal tract. Preliminary analyses indicated that bile decreases the sensitivity of $C$. albicans against a wide variety of commonly used antifungals, implying that the gall bladder forms a protective niche during antifungal therapy (Jacobsen et al., 2014).

Candida albicans infections of the liver and biliary system have been described as a major complication in liver transplant recipients (Romero and Razonable, 2011; Hernandez Mdel et al., 2015) and a prophylactic therapy with antifungals, mainly with fluconazole or echinocandins is recommended (Hernandez Mdel et al., 2015). However, while a case study on a liver transplant recipient suffering from Candida cholangitis recommended caspofungin for treatment of biliary infections (Goicoechea et al., 2004) the study showed that despite parenteral caspofungin therapy fluconazole sensitive $C$. albicans could still be isolated from bile samples (Goicoechea et al., 2004). Another clinical case report showed that conventional amphotericin $\mathrm{B}$ failed to control candidemia in the gall bladder (Jajoo et al., 2012) and in a clinical case series Candida bile duct infections were linked to treatment failure in some patients (Domagk et al., 2006). Additional studies indicate that treatment of fungal infections of the biliary system appears to present a more general problem. One study showed that antifungal therapy was ineffective in a biliary Coccidioides immitis infection (Sydorak et al., 2001). In another case report early hepatic artery thrombosis due to bacterial and Aspergillus infection occurred in a liver transplant recipient. Despite antibiotic and amphotericin B treatment the infection was not resolved and a revision of liver transplantation was required. It was speculated that the donor liver was the primary source of the infection (Jafarian et al., 2014). These studies indicate that the gall bladder may serve as a fungal infection reservoir not only in a murine model of candidiasis, but also in humans.

Due to the reduced susceptibility of $C$. albicans toward antifungals in the presence of bile and the described problems of antifungal therapy in biliary tract infections we investigated the bile-mediated protective effect in more detail.
TABLE 1 | Oligonucleotides used in qRT-PCR experiments.

\begin{tabular}{ll}
\hline ECE1 & Forward: ACAGCCATGACTTCTGTTGC \\
UME6 & Reverse: ATCTGGAACGCCATCTCTCT \\
& Forward: TGGTAATGGCACTAACACCAA \\
HWP1 & Feverse: TGTAATCCAATTTAGCACAACC \\
& Reverse: TAATTGGCAGATGGTTGCAT \\
HGC1 & Forward: CAATTCTTCAACGTCATTAGGG \\
& Reverse: GCATTTGGGTGGTGGTATC \\
EFB1 & Forward: GTCGACTTGTTCGGTTCTGA \\
& Forward: ATGGACGGTGGTATGTITAG \\
ACT1 & Reverse: GAACAATGGATGGACCAGATTCGTCG
\end{tabular}

\section{MATERIALS AND METHODS}

\section{Strains and General Culture Conditions}

If not indicated otherwise, C. albicans strain SC5314 was used throughout all experiments. For studies on Tye7, strain SN152 tye $\Delta / \Delta$ and the corresponding wild-type strain SN152 were used (Noble and Johnson, 2005; Homann et al., 2009). Precultures were grown over night at $30^{\circ} \mathrm{C}$ in $20 \mathrm{ml} \mathrm{YPD}$ medium (per liter: $10 \mathrm{~g}$ yeast extract, $20 \mathrm{~g}$ peptone, and $20 \mathrm{~g}$ glucose). Cells were harvested by centrifugation at $4000 \times g$, washed twice in phosphate-buffered saline (PBS) and suspended in either YPD or MOPS-buffered RPMI 1640 (Sigma) with 2\% glucose (per liter: 10.4 g RPMI 1640, 34.53 g MOPS, 20 g glucose; $p H$ 6.8; subsequently defined as RPMI medium). Stock solution of caspofungin ( $5 \mathrm{mg} / \mathrm{ml}$; Cancidas ${ }^{\circledR}$, Merck, Germany), flucytosine (10 mg/ml), cycloheximide $(20 \mathrm{mg} / \mathrm{ml}$; Sigma C7698) or sodium azide $(20 \mathrm{mg} / \mathrm{ml})$ were prepared in PBS and filter sterilized. Amphotericin B stock solution was prepared at $4 \mathrm{mg} / \mathrm{ml}$ in DMSO. Fluconazole solution at $2 \mathrm{mg} / \mathrm{ml}$ was purchased from B. Braun, Germany. All drugs were diluted in the respective media that were used for sensitivity analyses. Controls were prepared according to the solvents used for stock solutions of the respective antibiotics.

\section{Preparation of Bile and Bile Salt Containing Media}

Bile stock solution (12.5\%) was prepared by dissolving crude porcine bile extract (Sigma, B8631) in RPMI or YPD. Insoluble components were removed by centrifugation at $12000 \times g$, the supernatant filter sterilized and stored at $4^{\circ} \mathrm{C}$ in the dark. Sodium taurodeoxycholate hydrate (Sigma, T0875), taurocholic acid sodium salt hydrate (Sigma, T4409), sodium glycocholate hydrate (Sigma, G7132), and unconjugated bile salts (UBS) (Sigma 48305, 50\% cholic acid sodium salt and 50\% deoxycholic acid sodium salt) were dissolved at $100 \mathrm{mg} / \mathrm{ml}$ in either YPD or RPMI, filtered and used as stock solutions.

\section{Drug Resistance Analyses}

Antifungal drug resistance or toxicity of bile salts was tested in broth dilution assays. Precultures of $C$. albicans yeasts were grown for $16 \mathrm{~h}$ in liquid $\mathrm{YPD}$, harvested by $10 \mathrm{~min}$ 

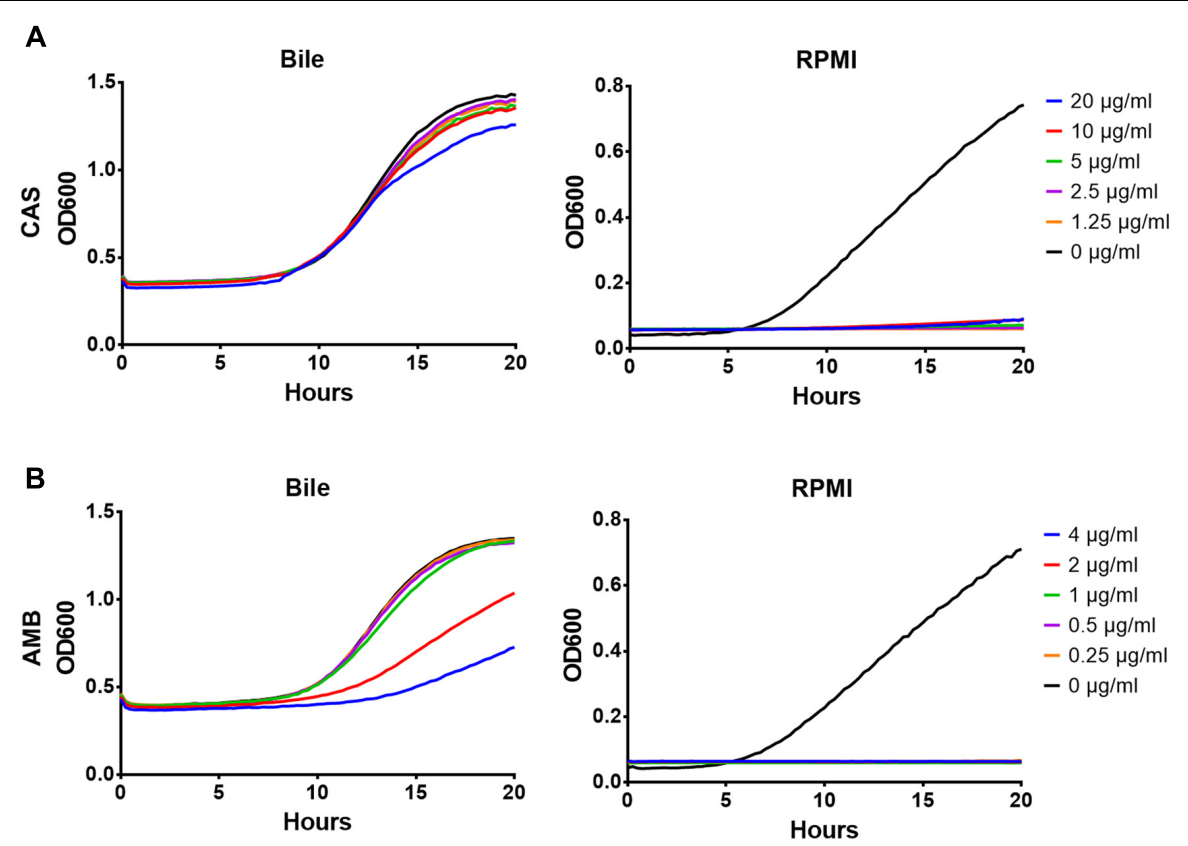

C

D
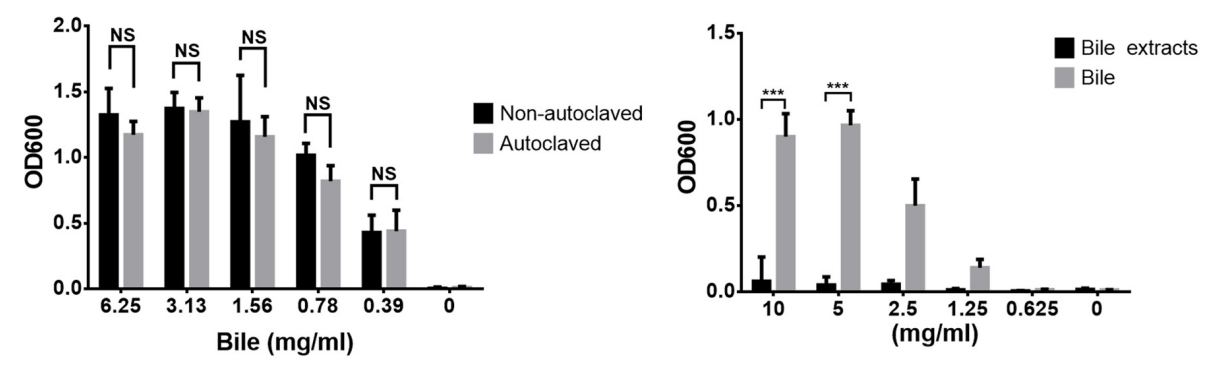

FIGURE 1 | Antifungal resistance against caspofungin and amphotericin B in presence of bile and bile extracts. Experiments were performed in biological and technical triplicates and mean values are shown. (A) Caspofungin resistance in RPMl/glucose medium with (left) and without (right) addition of bile. (B) Same as in (A), but with amphotericin B. (C) Endpoint analysis $(20 \mathrm{~h})$ of caspofungin $(5 \mu \mathrm{g} / \mathrm{ml})$ resistance in presence of heat-inactivated (autoclaved) and native reconstituted bile in RPMI/glucose medium. (D) Endpoint analysis of caspofungin resistance $(1 \mu \mathrm{g} / \mathrm{ml})$ in presence of an ethylacetate extract made from crude bile. Bar diagrams in (C) and (D) represent mean + SD. Significance was calculated using the two-tailed Student's $t$-test $\left({ }^{* * *} p<0.005, N S=\right.$ not significant).

centrifugation at $4000 \times g$ and washed twice in PBS. Dilutions of bile or bile salts with or without antifungals were prepared in either RPMI medium or YPD and transferred to 96-well plates. C. albicans cells were pre-diluted in the respective growth medium and added to a final concentration of $4 \times 10^{4}$ yeasts in $200 \mu \mathrm{l}$ medium. $\mathrm{NaCl}$ in YPD was used to test the effect of ionic strength. $\mathrm{pH}$ effects were tested in RPMI medium with MOPS buffer adjusted to different $\mathrm{pH}$ values. Resistance against $1 \mu \mathrm{g} / \mathrm{ml}$ caspofungin was evaluated in the presence of either $2.5 \mathrm{mg} / \mathrm{ml}$ sodium taurodeoxycholate or $10 \mathrm{mg} / \mathrm{ml}$ sodium taurocholate. All plates were sealed with transparent gas permeable moisture barrier seal (4titude) and incubated at $37^{\circ} \mathrm{C}$ for $20 \mathrm{~h}$, with $\mathrm{OD}_{600}$ measurements every 15 min preceded by $5 \mathrm{~s}$ shaking. Analyses were performed in triplicates with at least one biological replication. Data were analyzed by Microsoft Excel, and either growth curves or end point determinations are shown.

\section{Pre-adaptation Analyses}

Candida albicans cells were pre-incubated in YPD medium for $16 \mathrm{~h}$ at $30^{\circ} \mathrm{C}$ in the presence of $12.5 \%(\mathrm{w} / \mathrm{v})$ bile or $25 \mathrm{mg} / \mathrm{ml}$ sodium taurocholate (TC). Cells were washed once in PBS and transferred at an $\mathrm{OD}_{600}$ of 0.1 into 96-well plates containing MOPS-buffered RPMI with $2 \%$ glucose medium and different concentrations of amphotericin B or caspofungin and growth curves were recorded.

\section{Microarray Analyses}

YPD-grown cells were washed with PBS and transferred at $\mathrm{OD}_{600}$ of 0.1 to MOPS-buffered RPMI $2 \%$ glucose medium and grown for $4 \mathrm{~h}$ at $37^{\circ} \mathrm{C}$ on a rotary shaker at $180 \mathrm{rpm}$. Subsequently, parallel cultures were supplemented with either $25 \mathrm{mg} / \mathrm{ml} \mathrm{TC}$ or left as controls. Cells were harvested by centrifugation at 0.5 and $2 \mathrm{~h}$ and directly subjected to RNA extraction as previously described (Ramachandra et al., 2014). 

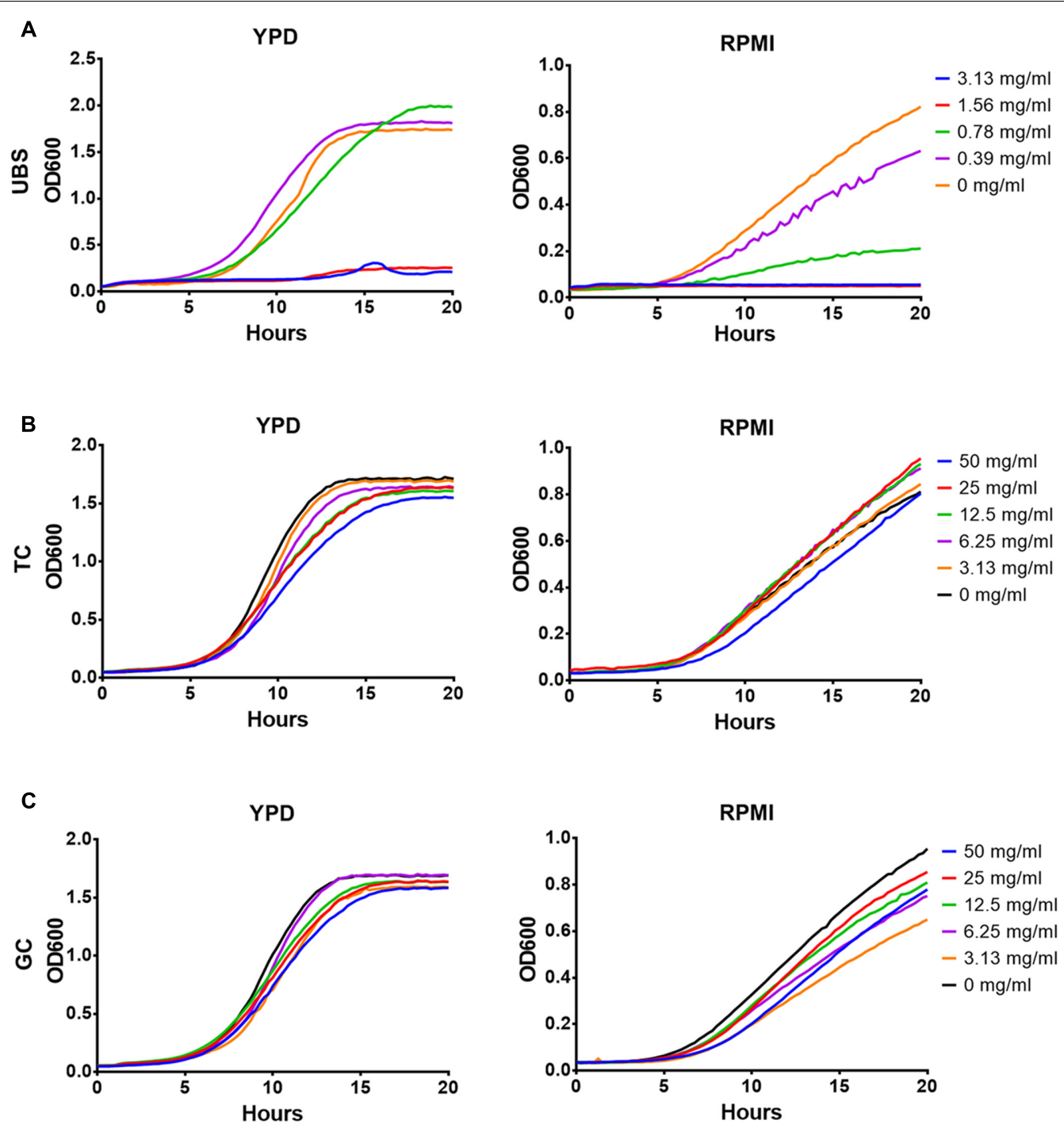

D

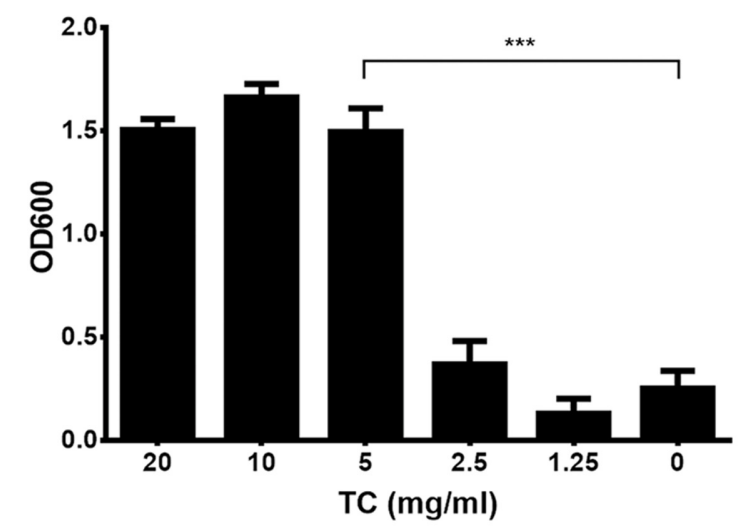

FIGURE 2 | Effect of unconjugated and conjugated bile salts on growth of Candida albicans. Mean data from three independent experiments are shown. Assays were performed in YPD or RPMI medium. (A) Growth in the presence of a serial dilution of unconjugated bile salts (UBS) consisting of a 1:1 mixture of sodium cholate and sodium deoxycholate. (B) Growth in presence of sodium taurocholate (TC). (C) Growth in presence of sodium glycocholate (GC). (D) Yeast cells were grown in the presence of $2 \mathrm{mg} / \mathrm{ml}$ UBS and different concentrations of TC. Bar diagrams show the mean + SD. Significance was calculated by two-tailed Student's t-test $(* * * p<0.005)$ 

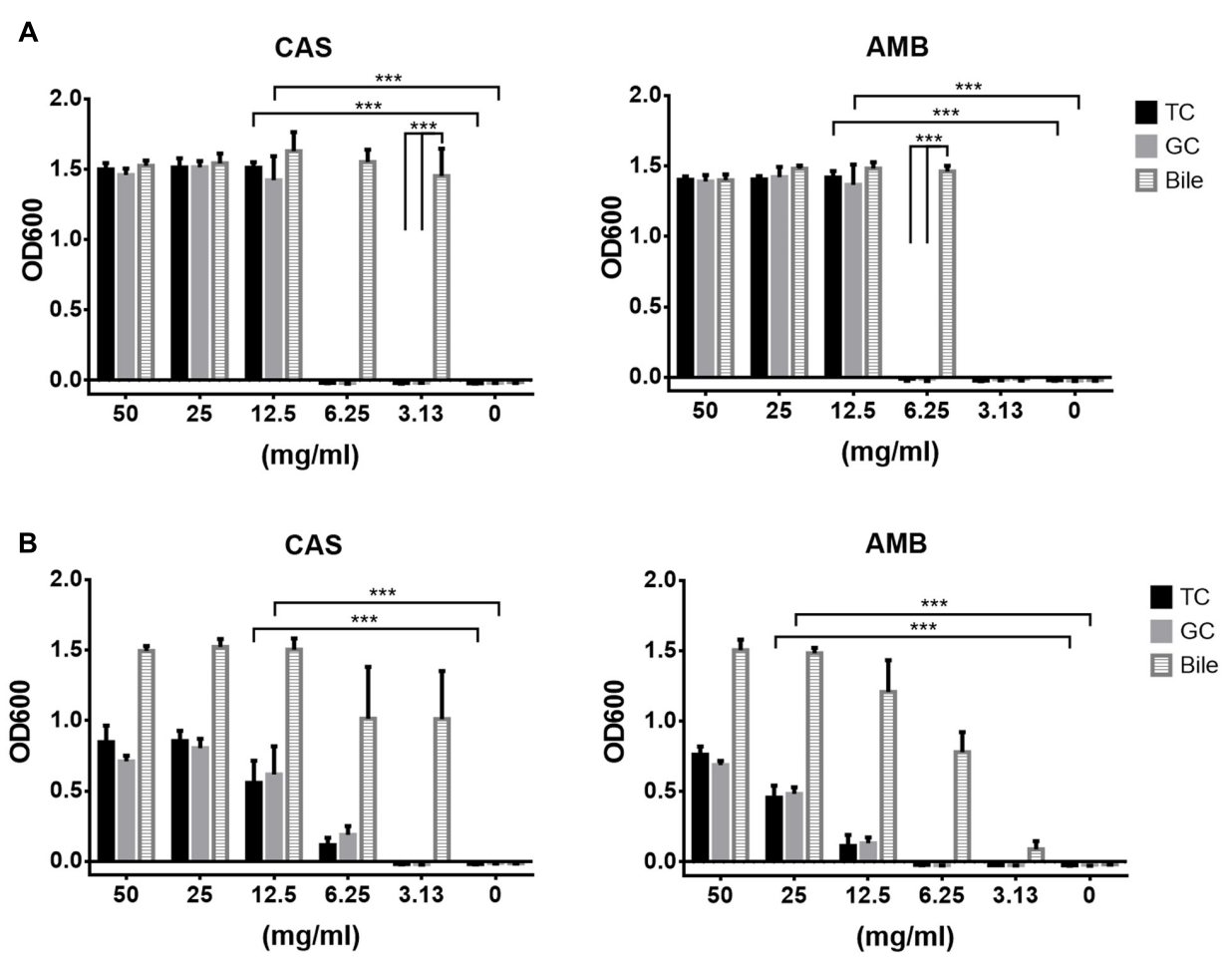

FIGURE 3 | Caspofungin and amphotericin B protection by bile, tauro- and glycocholate. C. albicans yeast cells were cultivated in presence of a fixed concentration of caspofungin (CAS, $1 \mu \mathrm{g} / \mathrm{ml}$ ) or amphotericin B (AMB, $0.5 \mu \mathrm{g} / \mathrm{ml}$ in RPMl and $2 \mu \mathrm{g} / \mathrm{ml}$ in YPD medium). Serial dilutions of either bile, taurocholate (TC) or glycocholate (GC) were added. Endpoint determinations after $20 \mathrm{~h}$ at $37^{\circ} \mathrm{C}$ are shown. (A) Analyses performed in YPD medium. (B) Analyses performed in RPMI/glucose medium. Bar diagrams show mean values + SD from three independent experiments. Statistical analyses were performed by using the two-tailed Student's $t$-test $(* * * p<0.005)$.

Microarrays were performed with Cy5-CTP labeled cRNA (GE Healthcare) using RNA from an exponentially growing C. albicans YPD liquid culture as Cy3-labeled common reference. Hybridisation, scanning and data analysis were performed as described (Ramachandra et al., 2014). The data was LOWESS normalized and evaluated using the GeneSpring GX software package, version 12.1 (Agilent). GO-Term analysis based on genome annotations from the Candida Genome Database (Inglis et al., 2012) was performed with the same program. Gene transcription data was deposited at the ArrayExpress database ${ }^{1}$ under accession number E-MTAB-5277.

\section{Quantitative Real Time PCR Analyses}

C. albicans yeast cells were incubated for 4 or $20 \mathrm{~h}$ at $37^{\circ} \mathrm{C}$ in MOPS-buffered RPMI 2\% glucose medium in presence or absence of $10 \mathrm{mg} / \mathrm{ml}$ TC. Cells were harvested by centrifugation, directly frozen in liquid nitrogen and RNA was extracted as described above. cDNA was produced by RevertAid Reverse Transcriptase (Thermo Scientific) with anchored oligo(dT) primers. qRT-PCR was analyzed on a CFX384 Touch RealTime PCR Detection System (BioRad, Munich, Germany) using EvaGreen $5 \times$ qPCR (ROX) mix (Bio \& Sell, Feucht, Germany). The ACT1 and EFB1 genes served as reference for

${ }^{1}$ www.ebi.ac.uk/arrayexpress
TABLE 2 | Expression of sulfur metabolism-related genes in Candida albicans.

\begin{tabular}{|c|c|c|c|c|}
\hline Selected genes & $\mathrm{TC}(0.5 \mathrm{~h})^{1}$ & RPMI (0.5 h) & $\mathrm{TC}(2 \mathrm{~h})^{1}$ & RPMI (2 h) \\
\hline MET2 ${ }^{\mathrm{a}}$ & -2.31 & -1.57 & -2.52 & -1.28 \\
\hline MET3 ${ }^{\mathrm{b}}$ & -3.39 & -1.86 & -2.41 & 1.24 \\
\hline MET10 & -11.68 & -5.22 & -9.38 & -1.93 \\
\hline MET14 & -2.06 & -1.63 & -2.43 & -1.16 \\
\hline MET15 & -5.37 & -3.11 & -2.69 & 1.04 \\
\hline MET16 & -2.48 & -1.86 & -2.10 & -1.80 \\
\hline
\end{tabular}

Expression levels are normalized against RNA from an exponentially growing YPD culture that was used as common reference.

${ }^{1} \mathrm{TC}=25 \mathrm{mg} / \mathrm{ml}$.

${ }^{a}$ Homoserine acetyltransferase; ${ }^{b}$ ATP sulfurlyase of sulfate assimilation; ${ }^{c}$ sulfite

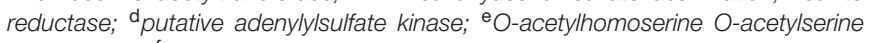
sulfhydrylase; ' putative 3'-phosphoadenylsulfate reductase.

normalization. Normalized transcript levels were expressed as fold expression $=\Delta 2^{\text {(reference }}$-target) based on expression levels in absence of TC. Oligonucleotide sequences are provided in Table 1.

\section{Farnesol Effects in Presence of} Taurocholic Acid

A $200 \mathrm{mM}$ ethanolic stock solution of trans, trans farnesol was diluted 1000-fold in MOPS-buffered RPMI 2\% glucose medium 


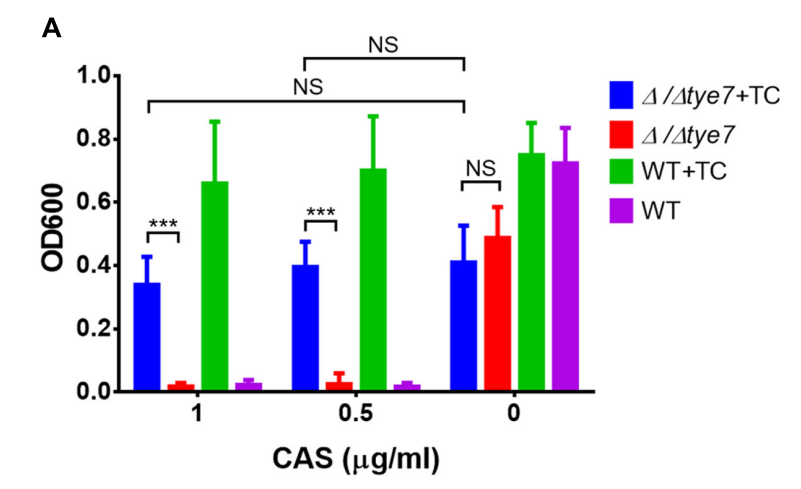

B

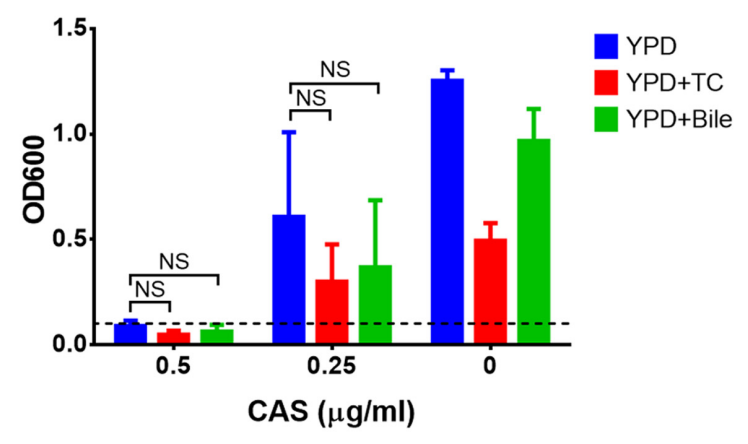

C

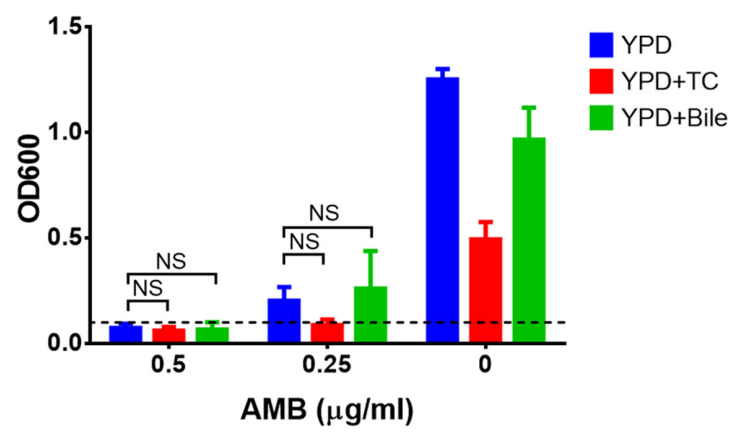

FIGURE 4 | Effect of tye7 gene deletion and pre-adaptation to bile or taurocholic acid on protection against antifungals. All data represent mean values + SD from three independent experiments and endpoint data after $20 \mathrm{~h}$ of incubation are shown. (A) Wild type (WT) and $\Delta / \Delta$ tye 7 mutant were grown in RPMl/glucose medium with or without $25 \mathrm{mg} / \mathrm{ml}$ taurocholate (TC) and varying concentrations of caspofungin $(0,0.5,1 \mu \mathrm{g} / \mathrm{ml})$. (B,C) C. albicans yeast cells were pre-incubated in YPD medium with or without $25 \mathrm{mg} / \mathrm{ml}$ taurocholate (TC) or $12.5 \mathrm{mg} / \mathrm{ml}$ bile. For sensitivity testing wells were inoculated at an $\mathrm{OD}_{600}$ of 0.1 (dashed line) and varying concentrations of (B) caspofungin or (C) amphotericin B were added. Growth was assessed after $20 \mathrm{~h}$ of incubation. Statistical significance was calculated by using the two-tailed Student's $t$-test $(* * * p<0.005$, NS $=$ not significant).

in presence or absence of $10 \mathrm{mg} / \mathrm{ml}$ TC. Shake flask cultures $(5 \mathrm{ml})$ were inoculated with $C$. albicans yeasts at an $\mathrm{OD}_{600}$ of 0.1 and incubated at $37^{\circ} \mathrm{C}$ and $180 \mathrm{rpm}$. Samples were removed at various time points and subjected to microscopy on a Zeiss Axiolmager M1.
TABLE 3 | Expression of hyphae-associated genes in C. albicans.

\begin{tabular}{|c|c|c|c|c|}
\hline Selected genes & $\mathrm{TC}(0.5 \mathrm{~h})^{1}$ & RPMI (0.5 h) & $\mathrm{TC}(2 \mathrm{~h})^{1}$ & RPMI (2 h) \\
\hline$E C E 1^{a}$ & 14.56 & 1.39 & 27.49 & 3.14 \\
\hline HWP $1^{\mathrm{b}}$ & 1.15 & -1.05 & 3.70 & 1.48 \\
\hline$H Y R 1^{c}$ & 2.61 & 2.10 & 2.29 & 2.24 \\
\hline$S O D 5^{\mathrm{d}}$ & 4.08 & 1.28 & 6.54 & 1.70 \\
\hline$I H D 1^{e}$ & -1.55 & -1.24 & 1.22 & -1.25 \\
\hline$R B T 1^{\dagger}$ & 1.28 & 1.15 & 1.53 & 1.26 \\
\hline
\end{tabular}

Expression levels are normalized against RNA from an exponentially growing YPD culture that was used as common reference.

${ }^{1} \mathrm{TC}=25 \mathrm{mg} / \mathrm{ml}$.

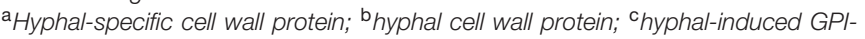
anchored cell wall protein; ${ }^{d}$ copper- and zinc-containing superoxide dismutase (induced by hyphal growth); ${ }^{\mathrm{e}}$ putative GPI-anchored protein (greater transcription in hyphal than yeast); ${ }^{\mathrm{f}}$ cell wall protein with similarity to Hwp1p.

A

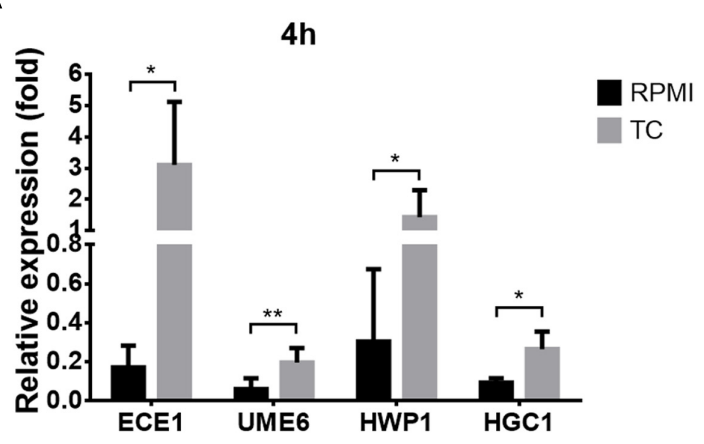

B

$20 \mathrm{~h}$

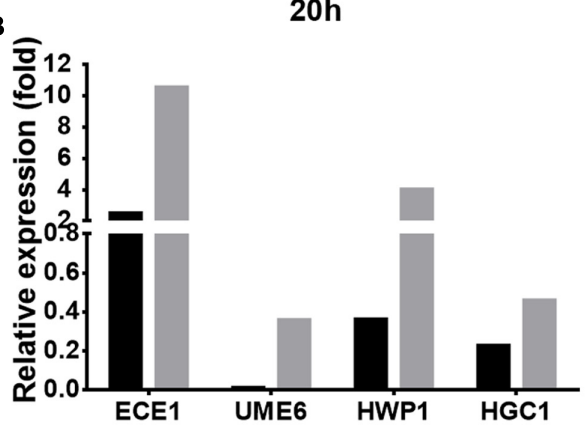

FIGURE 5 | Expression of hyphae-specific genes in the presence of conjugated bile salts. Expression of hyphae-specific genes ECE1, UME6, HWP1, and HCG1 was analyzed by qRT-PCR and normalized against actin gene (ACT1) expression. Cells were grown at $37^{\circ} \mathrm{C}$ in RPMI/glucose medium with or without the addition of $10 \mathrm{mg} / \mathrm{ml}$ taurocholate (TC). (A) Expression analysis at $4 \mathrm{~h}$ from three biological replicates in technical duplicates. Bar diagrams show mean values $+\mathrm{SD}$. Statistical significance was calculated by using the two-tailed Student's $t$-test with $* p<0.05$ and ${ }^{* *} p<0.01$.

(B) Expression analysis at $20 \mathrm{~h}$ from one biological sample as technical duplicate.

\section{Rhodamine 6G and Crystal Violet In- and Efflux Analyses}

Candida albicans yeasts were incubated at $30^{\circ} \mathrm{C}$ in MOPSbuffered RPMI $2 \%$ glucose medium in the presence of $1 \mu \mathrm{M}$ Rhodamine 6G (R6G) and various concentrations of bile or 


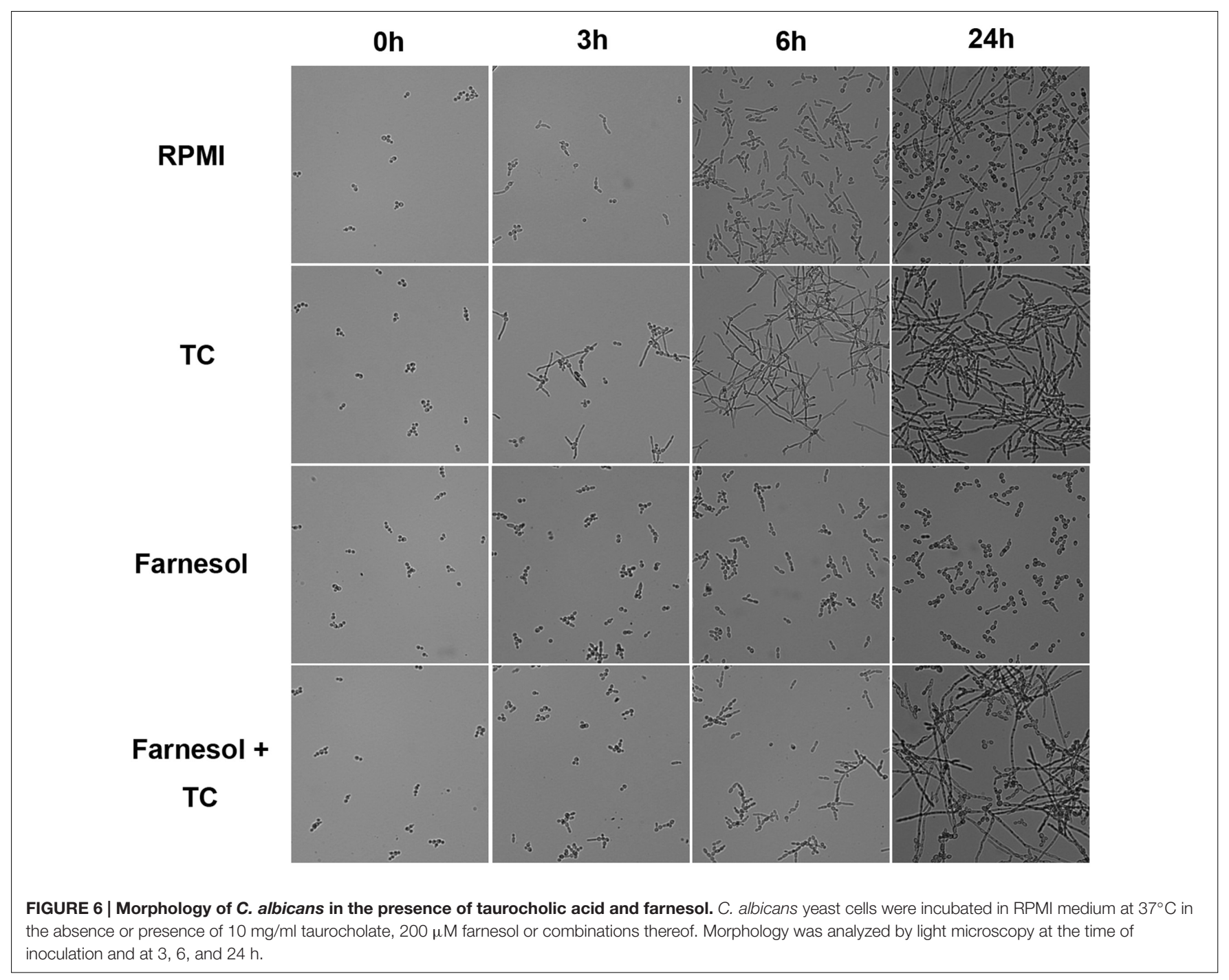

conjugated bile salts. Aliquots were harvested at different time points, washed twice with $50 \mathrm{mM}$ HEPES buffer $\mathrm{pH}$ 7.0. R6G fluorescence was measured in a microplate reader (Fluostar Omega, BMG Labtech) at $545 \mathrm{~nm}$ excitation and $590 \mathrm{~nm}$ emission. Fluorescence was normalized against $\mathrm{OD}_{600}$. For R6G efflux analyses, C. albicans yeasts were loaded for $30 \mathrm{~min}$ at $30^{\circ} \mathrm{C}$ with $1 \mu \mathrm{M}$ R6G. Yeast cells were collected by centrifugation and suspended in fresh media containing $1 \mu$ M R6G supplemented with either bile, sodium taurocholate or sodium taurodeoxycholate (all at final concentration of $5 \mathrm{mg} / \mathrm{ml}$ ) or left without supplementation. At different time points cells were harvested and washed once in HEPES buffer. The efflux of R6G was determined from the relative decrease of fluorescence from $\mathrm{OD}_{600}$ normalized cell densities. For crystal violet $(\mathrm{CV})$ absorption analyses yeasts were incubated for $30 \mathrm{~min}$ at $30^{\circ} \mathrm{C}$ in MOPS-buffered RPMI $2 \%$ glucose medium containing 2 or $4 \mu \mathrm{g} / \mathrm{ml} \mathrm{CV}$. As indicated media contained $5 \mathrm{mg} / \mathrm{ml}$ bile or conjugated bile salts and different concentrations $(0-80 \mathrm{mg} / \mathrm{ml})$ of $\mathrm{NaCl}$. Uptake of $\mathrm{CV}$ was visualized by photographs of cell pellets. Absorption rate was quantified at
$590 \mathrm{~nm}$ from supernatants after cell removal and compared to mock-inoculated medium. Relative $\mathrm{CV}$ absorption (\%) was calculated from $\left(\mathrm{A} 590_{\text {control }}-\mathrm{A} 590_{\text {sample }}\right) / \mathrm{A} 590_{\text {control }} \times 100$.

\section{Determination of CMC Values}

Critical micelle concentration (CMC) was determined as previously described (Patist et al., 2000) based on the change of absorbance of eosin Y during formation of micelles. In brief, $19 \mu \mathrm{M}$ of eosin $\mathrm{Y}$ were mixed with different concentrations of either bile or taurine conjugated bile salts and absorbance was measured at $542 \mathrm{~nm}$ in a 96-well plate using a microplate reader (Fluostar Omega, BMG Labtech). Absorbance was plotted against the $\log$ concentration of the solubilising agent for calculation of the CMC.

\section{Statistical Analyses}

Results in bar diagrams are shown as mean \pm standard deviation (SD). Growth curves depict mean values from technical and biological replicates. All experiments were performed in biological duplicates or triplicates with two or three wells 


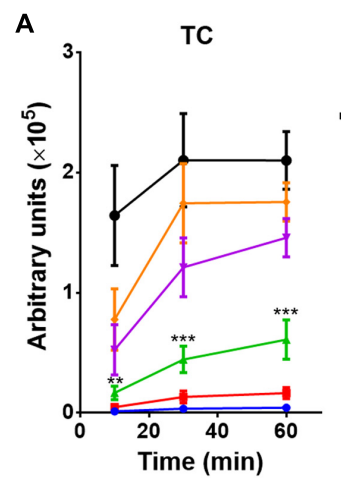

B

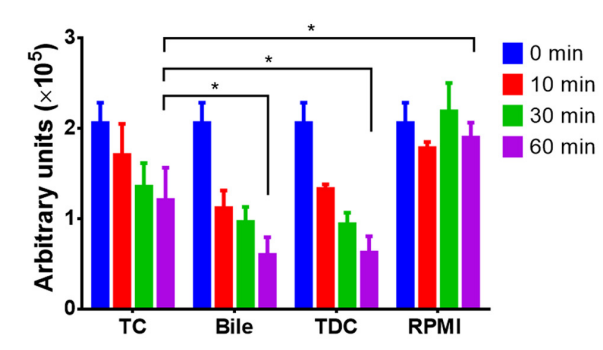

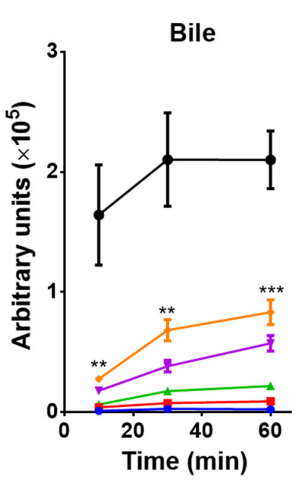

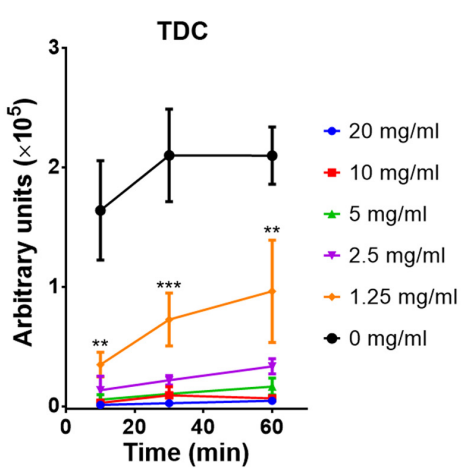

C

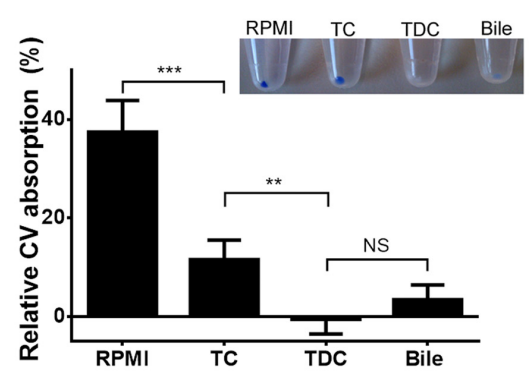

FIGURE 7 | Uptake and efflux of rhodamine 6 G and crystal violet (CV) in the presence of bile or conjugated bile salts. All data represent mean values + SD from three independent experiments. The Student's $t$-test was used for calculation of statistical significance $\left({ }^{*} p<0.05,{ }^{* *} p<0.01,{ }^{* * *} p<0.005\right.$, NS = not significant). (A) Time-dependent rhodamine 6G (R6G) uptake by C. albicans cells in the presence of serial dilutions of either taurocholate (TC), bile or taurodeoxycholate (TDC). Cells were harvested at indicated time points, washed and $\mathrm{OD}_{600}$-normalized R6G fluorescence was measured. Low fluorescence indicates low R6G absorption. Curves with asterisks indicate concentrations of TC $(5 \mathrm{mg} / \mathrm{ml})$, bile $(1.25 \mathrm{mg} / \mathrm{ml})$, and TDC $(1.25 \mathrm{mg} / \mathrm{ml})$ at which absorption significantly differs from the control. (B) R6G efflux assay. Yeast cells were pre-loaded with $1 \mu \mathrm{M} \mathrm{R6G}$ and shifted to R6G-containing media containing a fixed concentration (5 mg/ml) of either TC, bile or TDC. Efflux in presence of bile or TDC is significantly faster than with TC. (C) CV absorption by C. albicans in the presence or absence of $5 \mathrm{mg} / \mathrm{ml}$ of TC, TDC or bile. Inlay shows cell pellets after $30 \mathrm{~min}$ incubation with $2 \mu \mathrm{g} / \mathrm{ml} \mathrm{CV}$. The bar diagram shows the relative CV absorption from culture supernatants after $30 \mathrm{~min}$ of incubation in the presence of $4 \mu \mathrm{g} / \mathrm{ml} \mathrm{CV}$.

inoculated in parallel. Statistical significance was calculated using the two-tailed Student's $t$-test.

\section{RESULTS}

\section{Proteins, Phospholipids, and Cholesterol Do Not Protect against Antifungals}

Resistance analyses were performed in broth dilution assays in which porcine bile $(6 \% \mathrm{w} / \mathrm{v})$ was tested for its protective effect against caspofungin (CAS) and amphotericin B (AMB). As shown in Figures 1A,B, C. albicans was sensitive against CAS at $1.25 \mu \mathrm{g} / \mathrm{ml}$ (MIC $0.125 \mathrm{mg} / \mathrm{l}$ ), but nearly completely protected in the presence of bile even at $20 \mu \mathrm{g} / \mathrm{ml}$. Similarly, C. albicans was sensitive at $0.25 \mu \mathrm{g} / \mathrm{ml} \mathrm{AMB}(\mathrm{MIC}=0.063 \mathrm{mg} / \mathrm{l})$, but protected in the presence of bile although protection against $\mathrm{AMB}$ was less pronounced compared to CAS.

Bile solids consist of about $60 \%$ bile salts, $12 \%$ fatty acids, 9\% cholesterol, $7 \%$ proteins, and 3\% phospholipids and bilirubin (Farina et al., 2009). To elucidate the contribution of bile proteins (Dietschy, 1968; Pasternak et al., 2014) in protection, bile was heat-inactivated by autoclaving. Autoclaved bile showed the same protection as non-treated bile, indicating that no heatsensitive compounds were required for protection (Figure 1C).
Furthermore, an ethyl acetate extract prepared from bile did not protect against CAS (Figure 1D). These analyses imply that neither proteins nor fatty acids, phospholipids or cholesterol are protective against antifungals.

\section{Conjugated Bile Salts Are Well Tolerated by $C$. albicans}

Based on analyses above, we focused on conjugated and unconjugated bile salts. First, sensitivity analyses of C. albicans against possible toxic effects of unconjugated choline and deoxycholine in comparison to taurine and glycine conjugated choline were performed in YPD and RPMI medium (Figure 2). A mixture of choline and deoxycholine restricted growth in both media with an MIC of about $1.56 \mathrm{mg} / \mathrm{ml}$ (Figure 2A). In contrast, conjugated choline up to a concentration of at least $50 \mathrm{mg} / \mathrm{ml}$ was well tolerated, and no difference between taurocholate (TC) and glycocholate (GC) was observed (Figures 2B,C). Even more, $5 \mathrm{mg} / \mathrm{ml}$ of TC neutralized the toxic effects of $2 \mathrm{mg} / \mathrm{ml}$ of UBS (Figure 2D). Since conjugation of bile salts occurs directly within liver cells located at the periportal region of the liver conjugated bile salts are predominantly found in bile fluids (Solaas et al., 2000) with a concentration of about $40 \mathrm{mM}$ (Begley et al., 2005). De-conjugation mainly occurs within the intestine by bacterial degradation (Begley et al., 2005). Therefore, although bile fluids 
A

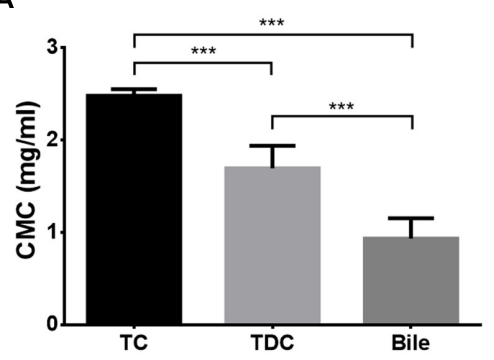

C

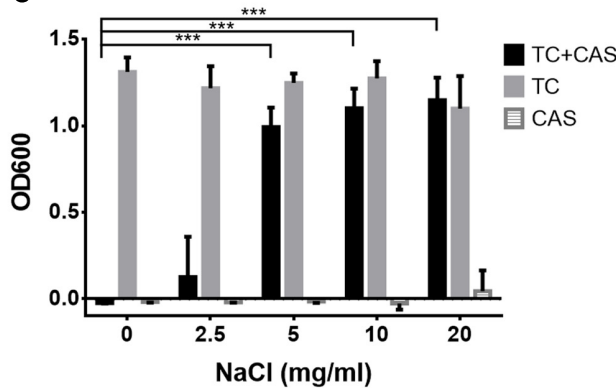

E

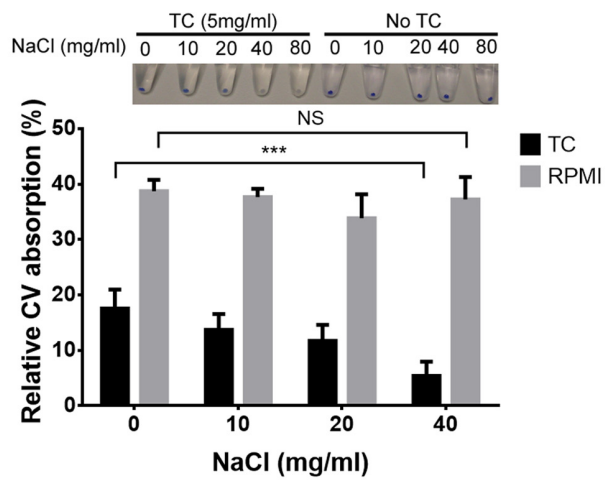

B

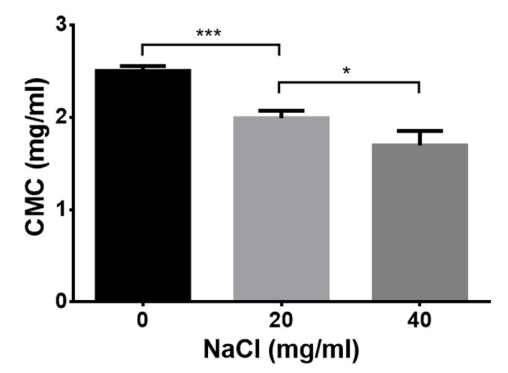

D

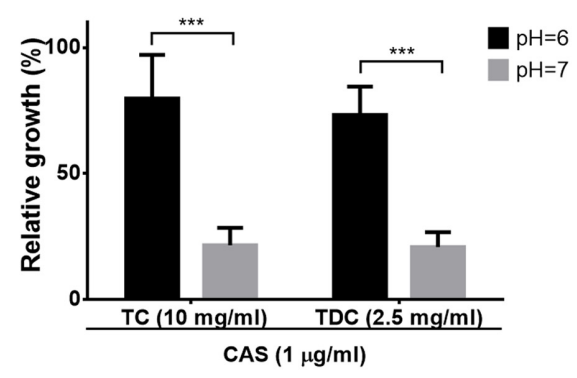

FIGURE 8 | Micelle formation and antifungal protection. All diagrams show mean values + SD from three independent experiments. (A) Determination of the critical micellar concentration (CMC) of TC, TDC and bile by using an eosin $Y$ assay. CMC values were calculated from trend lines based on the logarithm of the sample concentration against absorbance at $542 \mathrm{~nm}$. (B) Effect of increasing ionic strength on the CMC of TC. (C) Effect of increasing salt concentration on TC-mediated protection against caspofungin (CAS). Media contain a fixed concentration of either $10 \mathrm{mg} / \mathrm{ml} \mathrm{TC,} 2 \mu \mathrm{g} / \mathrm{ml}$ CAS or a combination of both. (D) Effect of $\mathrm{pH}$ on TC- $(10 \mathrm{mg} / \mathrm{ml})$ and TDC- $(2.5 \mathrm{mg} / \mathrm{ml})$ mediated protection against $1 \mu \mathrm{g} / \mathrm{ml} \mathrm{CAS}$. Data were normalized against control growth in the absence of CAS. (E) CV absorption in the presence of $5 \mathrm{mg} / \mathrm{ml} \mathrm{TC}$ at different ionic strength. Inlay photo shows the NaCl-dependent decolourisation of cell pellets. The bar diagram visualizes the relative $\mathrm{CV}$ absorption from the culture medium after $30 \mathrm{~min}$ of incubation. Statistical analyses were performed by the two-tailed Student's $t$-test $\left({ }^{*} p<0.05,{ }^{* * *} p<0.005, \mathrm{NS}=\right.$ not significant).

within the intestine may contain a significant proportion of UBS, their toxic effects on C. albicans can be neutralized by the remaining conjugated bile salts.

\section{Conjugated Bile Salts Confer Resistance of C. albicans against Antifungals}

To determine the protective effect of conjugated bile salts in comparison to bile, sensitivity tests in YPD (Figure 3A) and RPMI/glucose medium (Figure 3B) against CAS and AMB were performed. Indeed both, TC and GC were able to protect from antifungals in a concentration-dependent manner. Bile exhibited a full protective effect at about $3.1-6.3 \mathrm{mg} / \mathrm{ml}$ against both drugs, whereas a slightly higher concentration of about $12.5 \mathrm{mg} / \mathrm{ml}$ of conjugated bile salts was required for protection.

\section{Protection Does Not Require Expression of Specific Resistance Associated Genes}

Microarray analyses were performed to investigate the mechanism of antifungal protection in the presence of TC. Cells exponentially growing in YPD were shifted to RPMI/glucose medium with or without TC and gene expression was analyzed after 0.5 and $2 \mathrm{~h}$ of incubation. No clear pattern for the 


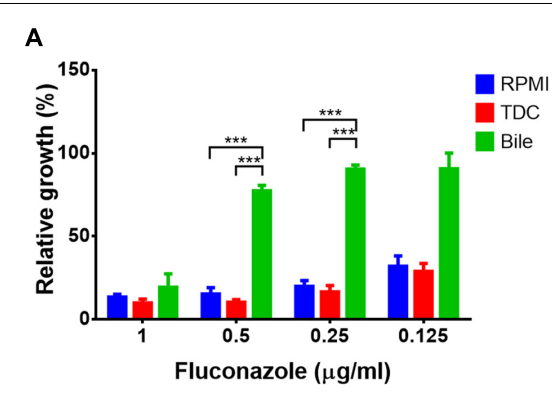

C

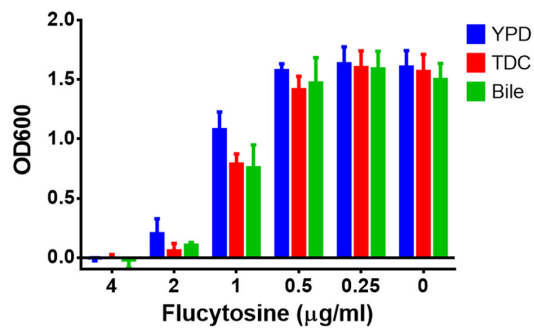

B

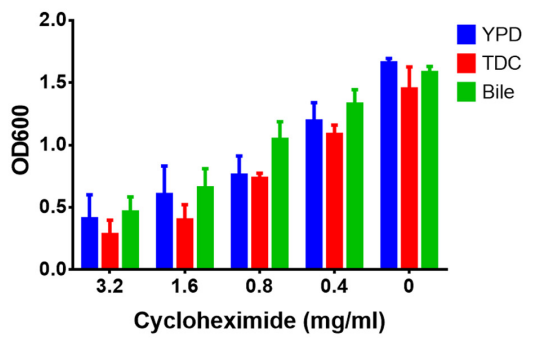

D

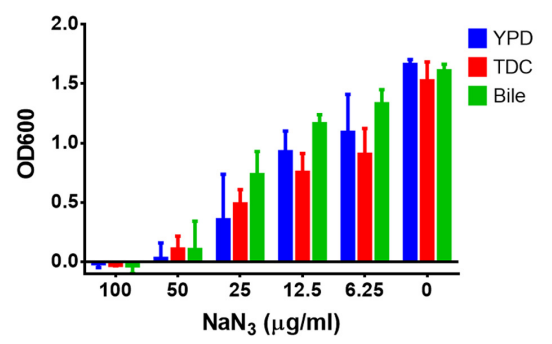

FIGURE 9 | Bile- and conjugated bile salt-mediated resistance against small and hydrophilic antifungals. Endpoint determination of growth after $20 \mathrm{~h}$ incubation at $37^{\circ} \mathrm{C}$. Bile $(12.5 \mathrm{mg} / \mathrm{ml})$ and taurodeoxycholic acid (TDC, $12.5 \mathrm{mg} / \mathrm{ml}$ ) or media controls were treated with serially diluted (A) fluconazole, (B) cycloheximide, (C) flucytosine, or (D) sodium azide. Bar diagrams represent the mean values + SD from three independent experiments. The Student's $t$-test was used for calculation of statistical significance $\left.{ }^{* * *} p<0.005\right)$.

upregulation of genes typically involved in drug resistance was observed, and the drug efflux pumps and transporters, such as Cdr1, Cdr2, and Mdr1 (Nakamura et al., 2001; Watamoto et al., 2011) showed similar expression patterns in presence or absence of TC. However, expression of genes involved in sulfur amino acid metabolism were downregulated indicating that the sulfur content of taurine from TC was sensed (Table 2). In contrast, hyphae-associated genes, such as ECE1 and HWP1 as well as the global regulator Tye7 (Askew et al., 2009) were upregulated. To analyze the impact of Tye7 on antifungal protection a tye $7 \Delta / \Delta$ mutant of $C$. albicans (Homann et al., 2009) was tested for its resistance against caspofungin in the presence of TC. Although the tye 7 mutant showed general reduction in growth rate, TC-mediated resistance was comparable to that of the parental strain (Figure 4A). Thus, Tye7 is not important for protection.

We subsequently tested if pre-incubation with bile or TC protects C. albicans. Cells were pre-grown in the presence of TC or bile, washed and challenged with CAS or AMB. Since both drugs remained inhibitory (Figures $4 \mathbf{B}, \mathbf{C}$ ), no pre-adaptation toward antifungals can be induced by bile or conjugated bile salts.

\section{Conjugated Bile Salts Block Quorum Sensing by Farnesol}

Microarray experiments revealed a strong upregulation of hyphae-specific genes in presence of TC (Table 3). qRT-PCR analyses confirmed upregulation of hyphae-associated genes after the transfer to TC containing medium at 4 and $20 \mathrm{~h}$ (Figure 5). This high gene expression levels during prolonged incubation was unexpected since $C$. albicans produces the quorum sensing molecule farnesol that triggers the reversal to yeast cells when exceeding a certain threshold level (Ramage et al., 2002; Langford et al., 2009). Therefore, morphological analyses were performed in RMPI/glucose medium, which triggers the initial formation of hyphae. Control cells cultivated without either farnesol or TC showed the expected morphological transitions (Figure 6): Pseudo- and true hyphae formed at early time points with an accumulation of hyphae after $6 \mathrm{~h}$. However, after $24 \mathrm{~h}$ a mixture of yeast and hyphal cells was detected, indicating a functional quorum sensing mechanism. Cells cultivated in the presence of TC formed hyphae at early time points that failed to switch back to yeast cells, and a $24 \mathrm{~h}$ culture consisted solely of hyphae (Figure 6). In contrast, cells cultivated in the presence of farnesol remained in yeast form throughout the $24 \mathrm{~h}$ observation period (Figure 6). In the presence of both, farnesol and TC the transition to hyphae was slightly delayed compared to TC alone. However, hyphae were produced and even after $24 \mathrm{~h}$ only small numbers of yeast cells were observed (Figure 6). This indicates that TC efficiently blocks farnesol signaling and implies that a similar mechanism might hold true for the protection from antifungals. However, it should be mentioned that TC by itself does not act as a stimulus for hyphae formation. When cells were cultivated in YPD medium no transition into the hyphal morphology was observed by the addition of TC (not shown). Therefore, experiments on drug sensitivity performed in YPD medium resemble planktonic yeast growth, whereas those in RPMI medium resemble hyphal growth within tissues.

\section{Bile and Conjugated Bile Salts Block Rhodamine 6G and Crystal Violet Absorption}

Rhodamine 6G (R6G) is a fluorescent dye that is used as a model compound in drug influx and efflux studies (Nakamura 
et al., 2001; Saengkhae et al., 2003). In- and efflux of R6G was investigated in the presence of bile, TC or taurine conjugated deoxycholic acid (TDC), another major bile component. As shown in Figure 7A, influx of R6G was blocked by all three additives, although a clear dependence on the specific bile compound was observed. While at least $5 \mathrm{mg} / \mathrm{ml}$ of TC were required to block the uptake of $\mathrm{R} 6 \mathrm{G}, 1.25 \mathrm{mg} / \mathrm{ml}$ of bile or TDC already blocked influx. Similarly, all three compounds triggered the efflux of R6G when applied at a concentration of $5 \mathrm{mg} / \mathrm{ml}$, with a significantly faster efflux in presence of bile or TDC than with TC (Figure 7B). These results suggested that bile and conjugated bile salts can protect $C$. albicans from antifungals in a dose-dependent manner by interacting with drugs in the growth medium. Results also implied that TDC might possess a higher protective potential than TC. Indeed, when antifungal protection against amphotericin B and caspofungin was tested with all three compounds, bile and TDC required the same concentration for protection $(2.5 \mathrm{mg} / \mathrm{ml}$ for amphotericin $\mathrm{B}$ and $5 \mathrm{mg} / \mathrm{ml}$ for caspofungin), whereas higher concentrations were required for protection by TC $(10 \mathrm{mg} / \mathrm{ml})$. Finally, when the absorption of the toxic compound $\mathrm{CV}$ was investigated, TC, TDC and bile significantly reduced $\mathrm{CV}$ absorption, with TDC and bile being more effective than TC (Figure 7C).

\section{Critical Micelle Concentration Correlates with Antifungal Protection}

Bile solubilises hydrophobic and amphiphilic molecules by forming mixed micelles (Begley et al., 2005). However, micelle formation only occurs when a so-called critical micellar concentration (CMC) is exceeded. Due to the different concentrations of bile, TC and TDC required in the R6G and $\mathrm{CV}$ in- and efflux experiments, CMC values were determined for all three compounds (Figure 8A). Indeed, CMC values of bile and TDC were significantly lower than that of TC with bile showing the lowest CMC. To confirm that CMC determines protection, conditions that reduce CMCs such as increased salt concentration or lowered $\mathrm{pH}$ were tested (Sugihara et al., 1982) (Figure 8B). Indeed, lower concentrations of TC or TDC were required for protection against CAS when either ionic strength was increased or the $\mathrm{pH}$ lowered (Figures 8C,D). Similarly, absorption of $\mathrm{CV}$ in presence of $5 \mathrm{mg} / \mathrm{ml} \mathrm{TC}$ was reduced when the salt concentration was increased (Figure 8E). This confirms trapping of antifungals in micelles, thereby reducing their bioavailability.

\section{Small and Hydrophilic Drugs Remain Active in Presence of Conjugated Bile Salts}

As bile and conjugated bile salts are very effective in solubilising hydrophobic and amphiphilic compounds, we assumed that small and hydrophilic compounds might be less efficiently trapped in micelles. Therefore, the protective effect against other antifungal compounds, such as fluconazole, cycloheximide, flucytosine, and sodium azide was tested. The efficacy of fluconazole was dramatically decreased in the presence $12.5 \mathrm{mg} / \mathrm{ml}$ bile, whereas the same concentration of TDC was not protective (Figure 9A). When cycloheximide (Figure 9B), flucytosine (Figure 9C), or sodium azide (Figure 9D) were tested, neither bile nor TDC were protective. This suggests that bile and conjugated bile salts cannot efficiently trap small and hydrophilic compounds in mixed micelles.

\section{DISCUSSION}

Recently, studies on a murine infection model showed that C. albicans is protected from antifungals inside the gall bladder and shed cells survive the passage through the bile duct and intestine (Jacobsen et al., 2014). Therefore, gall bladder colonization in patients might act as a reservoir for recolonization of the intestine after discontinuation of antifungal therapy. Here, we show the relevance of micelle formation by conjugated bile salts as the major mechanism of protection.

Bile salts have the potential to inactivate pathogens (Hofmann, 1999) and, in agreement, UBS showed toxic effects on C. albicans. However, conjugation of bile salts with either taurine or glycine reduced their toxicity and, in a mixture, were able to detoxify UBS. Therefore, conjugation of bile salts seems essential for C. albicans to colonize the gall bladder. However, a specific transcriptional response toward conjugated bile salts seems of minor importance for the protection from antifungals. Despite upregulation of glycolysis and hyphae-associated genes no clear pattern for the upregulation of resistance-associated genes was observed (Mathe and Van Dijck, 2013). Some of the observed changes in gene expression may result from blocking of the quorum sensing molecule farnesol (Wongsuk et al., 2016), which is in agreement with the early formation of true hyphae and cultures remaining in hyphal morphology even at high cell densities. This effect of conjugated bile salts could possibly counteract the known synergistic effects of farnesol with antifungals in the treatment of fungal (Katragkou et al., 2015) or mixed species (Fernandes et al., 2016) biofilms.

In our experiments bile or conjugated bile salts prevented influx and promoted efflux of drugs as shown for the model compounds R6G and CV. While bile salts can act as socalled "enabling formulations" to increase the bioavailability of drugs with poor dissolution characteristics (Buckley et al., 2013), bioavailability requires the release of drugs from micelles for crossing membranes of target cells. This is dependent on the equilibrium of drugs free in solution and drugs bound in micelles (Yano et al., 2010). However, significant differences in the encapsulation capability between bile and its conjugated bile salts seem to exist. When testing 30 different compounds, free drug concentration of some compounds was reduced by either bile or a mixture of taurocholate and lecithin, whereas other drugs were only encapsulated by bile (Berginc et al., 2012). This reflects our investigations, in which CAS and AMB were encapsulated by both, bile and conjugated bile salts, whereas fluconazole remained active with TC or TDC, but was inactivated by bile. This may be a result of the more complex composition of bile, which forms more variable mixed micelles that possess higher drug binding capacities than those made of pure conjugated bile salts. The presence of cholesterol in bile samples may 
also at least partially contribute to the increased protective effect of bile against fluconazole. Investigations on Aspergillus fumigatus showed that cholesterol increased resistance against itraconazole by incorporation of cholesterol into the fungal cell membrane. However, a much lower protective effect was observed when voriconazole was used, which indicates that cholesterol incorporation on its own is not sufficient for a general azole resistant phenotype (Xiong et al., 2005). In this respect, it should be noted that the ethyl acetate extract of bile containing phospholipids, fatty acids and cholesterol was not protective against various drugs tested. Nevertheless, future studies will have to investigate the increased efficiency of drug inactivation from mixed micelles by combining conjugated bile salts with phospholipids, unsaturated fatty acids and cholesterol.

Caspofungin, which shows excellent efficacies in treatment of systemic infections gets inactivated by bile and bile salts and, in agreement, failed in a case series for treatment of biliary tract infections (Domagk et al., 2006). In addition, a recent study on fungal cholangitis patients after liver transplantation revealed a reduced bioavailability of different $\mathrm{AMB}$ formulations in bile. The maximum concentration of AMB detected in one of the human bile samples was $1.28 \mathrm{mg} / \mathrm{l}$, but in vitro studies showed that up to $5 \mathrm{mg} / \mathrm{l}$ of AMB added to human bile samples did not inactivate $C$. albicans or other Candida species leading to the conclusion that a reliable treatment success on fungal cholangitis with AMB cannot be anticipated (Welte et al., 2015). This underlines our results on the reduced bioavailability of antifungals by micelle formation. Importantly, a recent study on echinocandin resistant Candida spp. in liver transplant recipients revealed the emergence of resistant isolates within one months after initiation of treatment (Prigent et al., 2016). At least three resistant $C$. albicans isolates were isogenic to susceptible isolates from the same patient, indicating that resistance occurred under the selective pressure of echinocandin treatment. While some resistant Candia spp. were isolated from multiple body site, resistant isolates were overrepresented in samples collected from the anus region. It was speculated that sub-inhibitory drug

\section{REFERENCES}

Akpan, A., and Morgan, R. (2002). Oral candidiasis. Postgrad. Med. J. 78, 455-459. doi: $10.1136 / \mathrm{pmj} .78 .922 .455$

Askew, C., Sellam, A., Epp, E., Hogues, H., Mullick, A., Nantel, A., et al. (2009). Transcriptional regulation of carbohydrate metabolism in the human pathogen Candida albicans. PloS Pathog. 5:e1000612. doi: 10.1371/journal.ppat.1000612

Begley, M., Gahan, C. G., and Hill, C. (2005). The interaction between bacteria and bile. FEMS Microbiol. Rev. 29, 625-651. doi: 10.1016/j.femsre.2004.09.003

Berginc, K., Trontelj, J., and Kristl, A. (2012). Bio-relevant media to assess drug permeability: sodium taurocholate and lecithin combination or crude bile? Int. J. Pharm. 429, 22-30. doi: 10.1016/j.ijpharm.2012.03.015

Buckley, S. T., Frank, K. J., Fricker, G., and Brandl, M. (2013). Biopharmaceutical classification of poorly soluble drugs with respect to "enabling formulations". Eur. J. Pharm. Sci. 50, 8-16. doi: 10.1016/j.ejps.2013.04.002

Cassone, A., and Cauda, R. (2012). Candida and candidiasis in HIV-infected patients: where commensalism, opportunistic behavior and frank pathogenicity lose their borders. AIDS 26, 1457-1472. doi: 10.1097/QAD.0b013e3283536ba8

Dietschy, J. M. (1968). Mechanisms for the intestinal absorption of bile acids. J. Lipid Res. 9, 297-309. concentrations may be present in the digestive system promoting the emergence of resistance (Prigent et al., 2016). In our previous study (Jacobsen et al., 2014), we found that C. albicans cells persisting under antifungal therapy in the gall-bladder are shed by bile and survive the intestinal passage. This shedding possibly leads to a re-colonization of the intestine. In agreement with the speculation above, encapsulation of drugs in micelles lowers their bioavailability to a sub-inhibitory concentration that might indeed facilitate the emergence of resistant isolates either directly within the biliary system or in the intestine. If this holds true, efficient monitoring of fungal bile infections in patients at risk for invasive fungal infections should be considered.

The strong reduction of antifungal efficacy of several drugs in the presence of bile may make it difficult to resolve fungal infections within the biliary tract. However, neither bile nor conjugated bile salts were able to efficiently encapsulate small and hydrophilic compounds, such as cycloheximide, flucytosine, or sodium azide. Therefore, if susceptibility profiling allows, antifungals that are difficult to trap in micelles should be considered when treating fungal infections of the biliary tract.

\section{AUTHOR CONTRIBUTIONS}

$\mathrm{S}-\mathrm{HH}$ designed and performed experiments and evaluated data, SB planned and evaluated microarray experiments, $\mathrm{MB}$ designed experiments, evaluated data, and wrote the manuscript. All authors critically revised the manuscript, approved it for publication and agree to be accountable for the content of the work.

\section{FUNDING}

This work was supported by the Jena School of Microbial Communication (JSMC) and by the School of Life Sciences of the University of Nottingham.

Domagk, D., Fegeler, W., Conrad, B., Menzel, J., Domschke, W., and Kucharzik, T. (2006). Biliary tract candidiasis: diagnostic and therapeutic approaches in a case series. Am. J. Gastroenterol. 101, 2530-2536. doi: 10.1111/j.1572-0241.2006. 00663.x

Farina, A., Dumonceau, J. M., and Lescuyer, P. (2009). Proteomic analysis of human bile and potential applications for cancer diagnosis. Expert Rev. Proteomics 6, 285-301. doi: 10.1586/epr.09.12

Fernandes, R. A., Monteiro, D. R., Arias, L. S., Fernandes, G. L., Delbem, A. C., and Barbosa, D. B. (2016). Biofilm formation by Candida albicans and Streptococcus mutans in the presence of farnesol: a quantitative evaluation. Biofouling 32, 329-338. doi: 10.1080/08927014.2016.1144053

Gavalda, J., Meije, Y., Fortun, J., Roilides, E., Saliba, F., Lortholary, O., et al. (2014). Invasive fungal infections in solid organ transplant recipients. Clin. Microbiol. Infect. 20(Suppl. 7), 27-48. doi: 10.1111/1469-0691.12660

Goicoechea, M., Fierer, J., and Johns, S. (2004). Treatment of candidal cholangitis with caspofungin therapy in a patient with a liver transplant: documentation of biliary excretion of caspofungin. Clin. Infect. Dis. 38, 1040-1041. doi: 10.1086/ 382082

Gullo, A. (2009). Invasive fungal infections: the challenge continues. Drugs 69(Suppl. 1), 65-73. doi: 10.2165/11315530-000000000-00000 
Hernandez Mdel, P., Martin, P., and Simkins, J. (2015). Infectious complications after liver transplantation. Gastroenterol. Hepatol. (N.Y.) 11, 741-753.

Hofmann, A. F. (1999). The continuing importance of bile acids in liver and intestinal disease. Arch. Intern. Med. 159, 2647-2658. doi: 10.1001/archinte.159. 22.2647

Homann, O. R., Dea, J., Noble, S. M., and Johnson, A. D. (2009). A phenotypic profile of the Candida albicans regulatory network. PLoS Genet. 5:e1000783. doi: 10.1371/journal.pgen.1000783

Inglis, D. O., Arnaud, M. B., Binkley, J., Shah, P., Skrzypek, M. S., Wymore, F., et al. (2012). The Candida genome database incorporates multiple Candida species: multispecies search and analysis tools with curated gene and protein information for Candida albicans and Candida glabrata. Nucleic Acids Res. 40, D667-D674. doi: 10.1093/nar/gkr945

Jacobsen, I. D., Lüttich, A., Kurzai, O., Hube, B., and Brock, M. (2014). In vivo imaging of disseminated murine Candida albicans infection reveals unexpected host sites of fungal persistence during antifungal therapy. J. Antimicrob. Chemother. 69, 2785-2796. doi: 10.1093/jac/dku198

Jafarian, A., Kasraianfard, A., and Nassiri-Toosi, M. (2014). Revision liver transplant for persistent infection and localized aspergillosis after hepatic artery thrombosis. Exp. Clin. Transplant 12, 381-383. doi: 10.6002/ect.2013.0129

Jajoo, M., Kumar, V., Goyal, V. K., and Garg, A. (2012). Candida tropicalis infection in a term neonate with gall bladder masses and infective endocarditis. Asian Pac. J. Trop. Med. 5, 410-412. doi: 10.1016/S1995-7645(12)60069-8

Katragkou, A., McCarthy, M., Alexander, E. L., Antachopoulos, C., Meletiadis, J., Jabra-Rizk, M. A., et al. (2015). In vitro interactions between farnesol and fluconazole, amphotericin B or micafungin against Candida albicans biofilms. J. Antimicrob. Chemother. 70, 470-478. doi: 10.1093/jac/dku374

Langford, M. L., Atkin, A. L., and Nickerson, K. W. (2009). Cellular interactions of farnesol, a quorum-sensing molecule produced by Candida albicans. Future Microbiol. 4, 1353-1362. doi: 10.2217/fmb.09.98

Li, X., Hou, Y., Yue, L., Liu, S., Du, J., and Sun, S. (2015). Potential targets for antifungal drug discovery based on growth and virulence in Candida albicans. Antimicrob. Agents Chemother. 59, 5885-5891. doi: 10.1128/AAC.00726-15

Mathe, L., and Van Dijck, P. (2013). Recent insights into Candida albicans biofilm resistance mechanisms. Curr. Genet. 59, 251-264. doi: 10.1007/s00294-0130400-3

Matthaiou, D. K., Christodoulopoulou, T., and Dimopoulos, G. (2015). How to treat fungal infections in ICU patients. BMC Infect. Dis. 15:205. doi: 10.1186/ s12879-015-0934-8

Nakamura, K., Niimi, M., Niimi, K., Holmes, A. R., Yates, J. E., Decottignies, A., et al. (2001). Functional expression of Candida albicans drug efflux pump Cdrlp in a Saccharomyces cerevisiae strain deficient in membrane transporters. Antimicrob. Agents Chemother. 45, 3366-3374. doi: 10.1128/AAC.45.12.33663374.2001

Noble, S. M., and Johnson, A. D. (2005). Strains and strategies for large-scale gene deletion studies of the diploid human fungal pathogen Candida albicans. Eukaryot. Cell 4, 298-309. doi: 10.1128/EC.4.2.298-309.2005

Pasternak, A., Szura, M., Gil, K., Brzozowska, I., Maduzia, D., Mizia, E., et al. (2014). Metabolism of bile with respect to etiology of gallstone disease - systematic review. Folia Med. Cracov. 54, 5-16.

Patist, A., Bhagwat, S. S., Penfield, K. W., Aikens, P., and Shah, D. O. (2000). On the measurement of critical micelle concentrations of pure and technical-grade nonionic surfactants. J. Surfactants Deterg. 3, 53-58. doi: 10.1007/s11743-0000113-4

Prigent, G., Ait-Ammar, N., Levesque, E., Fekkar, A., Costa, J. M., El Anbassi, S., et al. (2016). Echinocandin resistance in Candida spp. isolated from liver transplant recipients. Antimicrob. Agents Chemother. doi: 10.1128/AAC.0122916 [Epub ahead of print].

Ramachandra, S., Linde, J., Brock, M., Guthke, R., Hube, B., and Brunke, S. (2014). Regulatory networks controlling nitrogen sensing and uptake in Candida albicans. PLoS ONE 9:e92734. doi: 10.1371/journal.pone.0092734

Ramage, G., Saville, S. P., Wickes, B. L., and Lopez-Ribot, J. L. (2002). Inhibition of Candida albicans biofilm formation by farnesol, a quorum-sensing molecule. Appl. Environ. Microbiol. 68, 5459-5463. doi: 10.1128/AEM.68.11.5459-5463. 2002

Romero, F. A., and Razonable, R. R. (2011). Infections in liver transplant recipients. World J. Hepatol. 3, 83-92. doi: 10.4254/wjh.v3.i4.83

Saengkhae, C., Loetchutinat, C., and Garnier-Suillerot, A. (2003). Kinetic analysis of rhodamines efflux mediated by the multidrug resistance protein (MRP1). Biophys. J. 85, 2006-2014. doi: 10.1016/S0006-3495(03)74628-1

Solaas, K., Ulvestad, A., Soreide, O., and Kase, B. F. (2000). Subcellular organization of bile acid amidation in human liver: a key issue in regulating the biosynthesis of bile salts. J. Lipid Res. 41, 1154-1162.

Sugihara, G., Yamakawa, K., Murata, Y., and Tanaka, M. (1982). Effects of Ph, Pna, and temperature on micelle formation and solubilization of cholesterol in aqueous-solutions of bile-salts. J. Phys. Chem. 86, 2784-2788.

Sydorak, R. M., Albanese, C. T., Chen, Y., Weintraub, P., and Farmer, D. (2001). Coccidioides immitis in the gallbladder and biliary tree. J. Pediatr. Surg. 36, 1054-1056. doi: 10.1053/jpsu.2001.24744

Teoh, F., and Pavelka, N. (2016). How Chemotherapy increases the risk of systemic candidiasis in cancer patients: current paradigm and future directions. Pathogens 5:E6. doi: 10.3390/pathogens5010006

Watamoto, T., Samaranayake, L. P., Egusa, H., Yatani, H., and Seneviratne, C. J. (2011). Transcriptional regulation of drug-resistance genes in Candida albicans biofilms in response to antifungals. J. Med. Microbiol. 60, 1241-1247. doi: 10. 1099/jmm.0.030692-0

Welte, R., Eschertzhuber, S., Weiler, S., Leitner-Rupprich, S., Aigner, M., Lass-Flörl, C., et al. (2015). Biliary amphotericin B pharmacokinetics and pharmacodynamics in critically ill liver transplant recipients receiving treatment with amphotericin B lipid formulations. Int. J. Antimicrob. Agents 46, 325-331. doi: 10.1016/j.ijantimicag.2015.04.009

Wongsuk, T., Pumeesat, P., and Luplertlop, N. (2016). Fungal quorum sensing molecules: role in fungal morphogenesis and pathogenicity. J. Basic Microbiol. 56, 440-447. doi: 10.1002/jobm.201500759

Xiong, Q., Hassan, S. A., Wilson, W. K., Han, X. Y., May, G. S., Tarrand, J. J., et al. (2005). Cholesterol import by Aspergillus fumigatus and its influence on antifungal potency of sterol biosynthesis inhibitors. Antimicrob. Agents Chemother. 49, 518-524. doi: 10.1128/AAC.49.2.518-524.2005

Yano, K., Masaoka, Y., Kataoka, M., Sakuma, S., and Yamashita, S. (2010). Mechanisms of membrane transport of poorly soluble drugs: role of micelles in oral absorption processes. J. Pharm. Sci. 99, 1336-1345. doi: 10.1002/jps.21919

Conflict of Interest Statement: The authors declare that the research was conducted in the absence of any commercial or financial relationships that could be construed as a potential conflict of interest.

Copyright $\odot 2017$ Hsieh, Brunke and Brock. This is an open-access article distributed under the terms of the Creative Commons Attribution License (CC BY). The use, distribution or reproduction in other forums is permitted, provided the original author(s) or licensor are credited and that the original publication in this journal is cited, in accordance with accepted academic practice. No use, distribution or reproduction is permitted which does not comply with these terms. 